International Journal of Engineering \& Technology, $7(1)(2018) 44-52$
SPC
International Journal of Engineering \& Technology
Website: www.sciencepubco.com/index.php/IJET
doi: $10.14419 /$ ijet. $v 7$ il. 8345
Research paper

\title{
Quantitative analysis of $0 \%$ infill density surface profile of printed part fabricated by personal FDM 3D printer
}

\author{
Mohammad S. Alsoufi* and Abdulrhman E. Elsayed \\ Department of Mechanical Engineering, College of Engineering and Islamic Architecture, Umm Al-Qura University, Makkah, KSA \\ *Corresponding author E-mail: mssoufi@uqu.edu.sa
}

\begin{abstract}
Fused deposition modeling or FDM technology is an additive manufacturing (AM) technology commonly used for prototyping applications which suffer seriously from low levels of fluctuated surface finish quality, demanding some hand finishing tool for even the necessary levels of 3D printed parts. This paper, therefore, aims at giving close attention to the variation in the surface roughness profile between the inner and the outer faces of FDM 3D printed parts based on advanced polylactic acid (PLA+) thermoplastic filament material. The surface roughness is quantitatively analyzed using a contact-type test-rig with a $90^{\circ}$ angle measurement on each face along with each zone and sub-zone. The obtained results revealed that the surface finish of the inner faces is rougher than those of the outer faces as regards nozzle temperature, nozzle diameter, infill density and layer height is $220^{\circ} \mathrm{C}, 0.5 \mathrm{~mm}, 0 \%$ and $0.3 \mathrm{~mm}$, respectively. The personal FDM 3D printer is thus confirmed to be an excellent platform, flexible, straightforward and cost-effective.
\end{abstract}

Keywords: Additive Manufacturing (AM), Fused Deposition Modeling (FDM), Surface Profile, 3D Printer.

\section{Background}

\subsection{Rapid Prototyping and 3D Printing}

Rapid prototyping (RP) refers to a collection of new technologies, such as fused deposition modeling (FDM), direct metal deposition (DMD), selective laser sintering (SLS), inject modeling (IJM) and stereolithography (SLA), which can be used to create any desired 3D physical model of a printed part, element, device or artefact faster than before without machining or tooling [1] by layer manufacturing from computer aided design (CAD) data [2] and without a significant increase in time or cost [3]. This rapid growth of the market has placed 3D printers not just in enormously varied industrial settings but also in schools, universities, and homes, and it is therefore often preferable to call these devices a 'personal 3D printer' or 'desktop 3D printer' $[4,5]$. The range of applications where FDM 3D printer technology can be used is widespread in different fields, ranging from medical [6] to automotive [7] and aeronautics applications [8]. Currently, as RP is moving towards rapid manufacturing, there is an increasing demand for obtaining good surface quality printed parts as this has more influence on how customers assess the quality of the $3 \mathrm{D}$ printed parts.

\subsection{FDM Technology}

Open source fused deposition modeling (FDM) is one of several RP technologies available that is currently attracting attention [9]. The FDM process was established commercially and sold to international trade in the early 1990s in the USA as a form of concept modeling by Stratasys Inc. [10]. Figure 1 shows the schematic concept of the FDM 3D printer process. It begins with a 3D model (or three-dimensional modeling) in a computer aided design (CAD) file in order to calculate the horizontal cross-sections at sufficiently small increments of the layer height of the printed part before converting it to an STL (Stereo-Lithography) format file [11]. The STL (Stereo-Lithography) format file is then treated by specific engineering software owned by AM technology which cuts the piece into small slices in order to acquire a new file containing descriptive information about each layer or path. This step implies G-code (geometric code) language to traduce the slicing in layers or paths $[12,13]$.

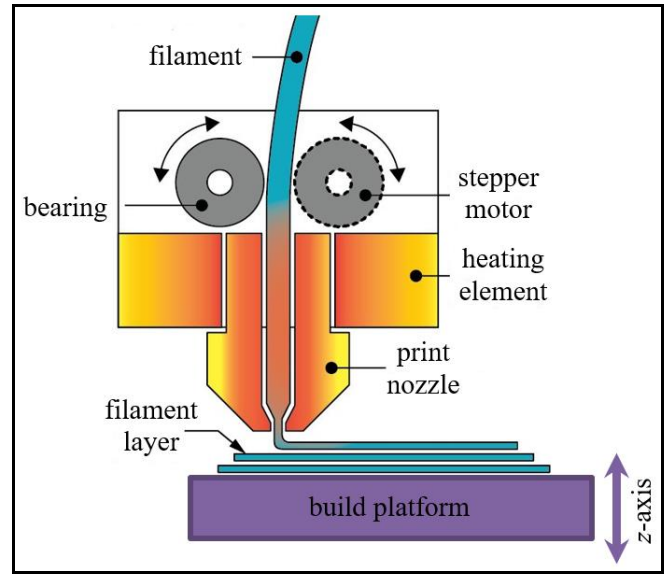

Fig. 1: FDM 3D extruded assembly

During the manufacturing process, the long-fiber thermoplastic filament material is heated up and melted down to a semi-liquid (partly liquid) state at room temperature. The semi-liquid (partly liquid) thermoplastic filament material is then extruded through the circular nozzle head which results in a cylindrical coiled morphology of each layer and then solidifies into the final desired shape. Bear in mind that the tip of the circular nozzle head moves both horizontally and vertically to draw the FDM 3D object directly from digital data (3D CAD design software) on a layer-by-layer 
or path-by-path basis in 'writing' mode. The layers or paths are merely created one at a time without changing the original image from the bottom layer on the platform to the top layer to complete the desired 3D printed part. After a layer is extruded, the extrusion head returns to its original position in the far-left corner. Through this depositing, the long-fiber thermoplastic filament material layer/path is defined to fill the product and also create a shell with often a striped shape at $45^{\circ}$ by alternate layers [12].

\subsection{Motivation}

Recently, an encouraging trend has emerged for using personal FDM 3D printing in the field of micro- and nano-technology (MNT) and the related lab-on-a-chip (LOC) field, which produces the functional parts in small batches, particularly in a rapid tooling application. Therefore, there is a clear need that the prototypes produced should have a high quality of surface finishing to ensure proper functional requirements.

Hence, in this paper, the authors thoroughly investigate the surface aspect of a prototype between the inner and outer four faces (four identical side walls) of $0 \%$ infill density. Figure 2 shows the proposed framework of the $0 \%$ infill density with four inner and outer identical faces. Moreover, it indicates that the test runs in laminar ambient temperature around the outer four identical faces, while it shows otherwise from the inner four identical faces as there is some turbulent ambient temperature present which will affect the surface roughness behaviour due to a solidification process from the outside wall to the inside wall as shown in Figure 2.

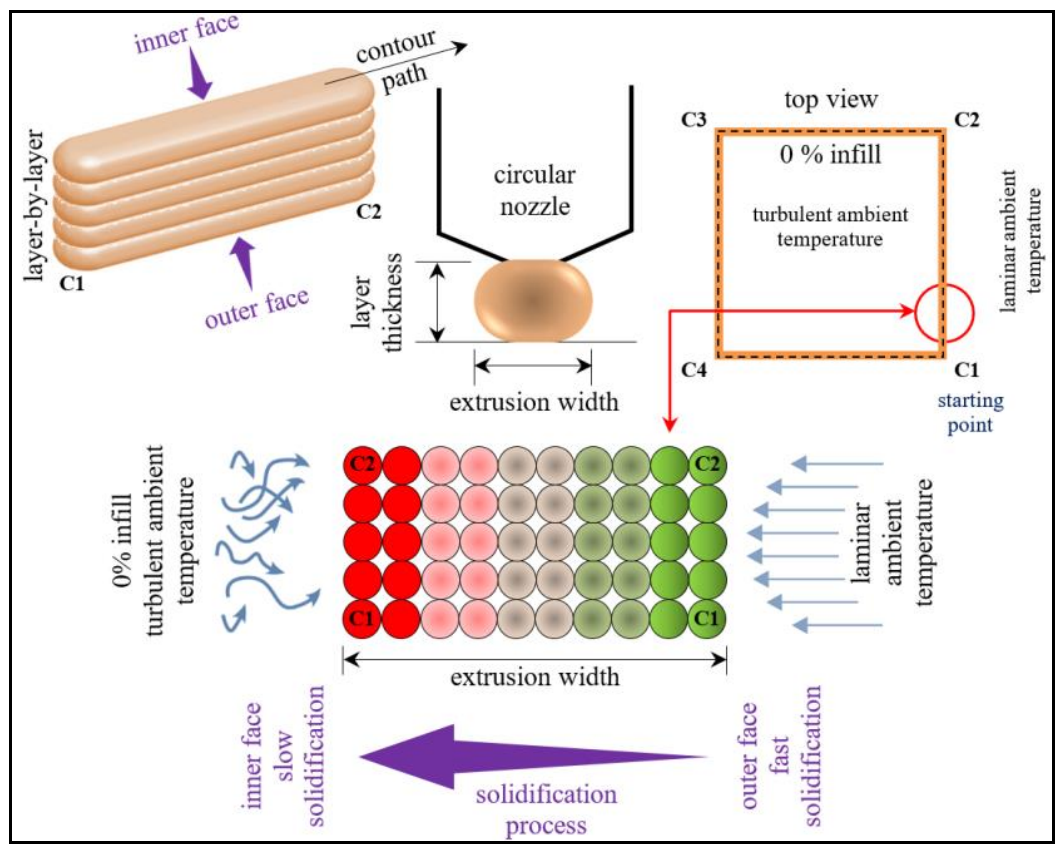

Fig. 2: proposed framework of the $0 \%$ infill density with inner and outer faces

\section{Experiment Procedure}

\subsection{D Printer}

The personal FDM 3D printer (do-it-yourself kits) used in this investigation was based on an open source digital model known as 'The BEAST', (available from Cultivate3D, Australia). For more details about the basic technical details, see [14-16]. This is a fully customized personal 3D printer which allows lightweight, lowcost, and very rapid prototyping compared to conventional machining (as with, for example, a CNC machine).

\subsection{Software and File Format}

Here, CATIA ${ }^{\circledR}$ V5 R20 as multi-platform software is used for 3D modeling design and is also suited to computer aided design (CAD). The 3D model design is then converted to an STL file using CATIA itself. The STL is a file format native to the STL CAD software created by the 3D model system. Many other software packages support this file format; it is widely used for RP and CAD. The KISSlicer PRO software assists the end-user in adjusting the build parameters and also generates path information, and a G-code (geometric code) is subsequently generated which controls the extrusion head of the personal FDM 3D printer. Each RP device possesses proprietary strategies for the conversion of the design to an FDM 3D printable format.

\subsection{Filament Material}

The long-fiber filament thermoplastic material used in this study for model fabrication was a commercially available advanced polylactic acid, PLA+, (eSUN PLA+ filament, the advanced formula by added extra bio-polyester blends) It is light blue coloured, $1.75 \mathrm{~mm}$ in diameter and showed $\pm 0.05 \mathrm{~mm}$ tolerance (Shenzhen Esun Industrial Co., Ltd.). According to company data sheets, it is made up of $100 \%$ bio-degradable thermoplastic polymers, derived from renewable sources (such as corn starch, sugarcane or tapioca roots) with the molecular formula $\left(\mathrm{C}_{3} \mathrm{H}_{4} \mathrm{O}_{2}\right)_{\mathrm{n}}$.

\subsection{Parameters Selection}

The surface finish quality of printed parts fabricated using FDM $3 \mathrm{D}$ technology depends on the careful selection of process parameters. In this work, the operating setup (standard) details of the personal FDM 3D printer are as follows: (1) the surface wall thickness is $0.5 \mathrm{~mm},(2)$ the infill density percentage is $0 \%$ and (3) the layer resolution is $200 \mu \mathrm{m}$. The weight of the proposed FDM 3D printed part with $0 \%$ infill density is approximately $5.9682 \mathrm{~g}$ using an electronic balance and it is relatively rigid. Table 1 shows a summary of the sample's technical properties and all other process parameters. The personal FDM 3D Printer process parameters were identified from a previous study reported in [14]. 
Table 1: summary of sample's technical properties and process parameters

\begin{tabular}{ll}
\hline Parameters & Values \\
\hline Filament Material & PLA+ (advanced polylactic acid) \\
Colour & Light Blue \\
Average Weight $(\mathbf{g})$ & 5.9682 \\
AM Process & FDM (Fused Deposition Modeling) \\
Layer Height $(\mathbf{m m})$ & 0.3 \\
Infill Density $(\%)$ & 0 \\
Nozzle Diameter $(\mathbf{m m})$ & 0.5 \\
Nozzle Temperature $\left({ }^{\circ} \mathbf{C}\right)$ & 220 \\
Printing Speed $(\mathbf{m m} / \mathbf{s})$ & 30 \\
Extrusion of Material $($ layer width) $(\mathbf{m m})$ & 0.48 \\
Speed for non-print $\mathbf{m o v e s}(\mathbf{m m})$ & 60 \\
Horizontal Shells $($ top and bottom layer) & 0 \\
Vertical Shells & 1 \\
Cooling Rate & Build-in \\
Bed Temperature $\left({ }^{\circ} \mathbf{C}\right)$ & Room Temperature \\
Room Temperature $\left({ }^{\circ} \mathbf{C}\right)$ & $25 \pm 1$ \\
Relative Humidity $(\%$ RH) & $40 \pm 5$ \\
\hline
\end{tabular}

\subsection{FDM 3D Geometry and Fabrication}

The specimen was produced using a personal FDM 3D printer from a single spool of PLA+ thermoplastic filament material at a nozzle temperature of $220^{\circ} \mathrm{C}$, layer height of $0.3 \mathrm{~mm}$, a nozzle diameter of $0.5 \mathrm{~mm}$ and a printing speed of $30 \mathrm{~mm} / \mathrm{s}$. The fabricating $0 \%$ infill density part was carried out on the top of a glass platform (flat build orientation with $0 / 90$ printing raster direction) that underneath has no heating bed and stands in an airconditioned room. Typically, the $z$-axis glass platform rises to its starting position at corner no.1 (C1) by just a few tenths of a mm from the material extrusion circular nozzle that protrudes from the liquefier (i.e., heating tube). The single extrusion head, which moves at approximately an $x-y$ axis platform, lays down a thin ribbon of thermoplastic filament material. After completion of a layer of forming, the $z$-axis build platform lowers very slightly to make room for the new layer of thermoplasticity. This rapid process is continued until the entire desired FDM 3D printed part is built as shown in Figure 3. It was decided that this would be kept very simple in terms of geometry and fabrication in order to enable the subsequent measurements: $40 \mathrm{~mm} \times 40 \mathrm{~mm} \times 55 \mathrm{~mm}$ square with $0 \%$ infill density. The build time was recorded from the $3 \mathrm{D}$ printing digital screen status on the machine itself, and it was just about 38 minutes and 57 seconds. During this test, there was no issue with a clogged nozzle or air bubbles.

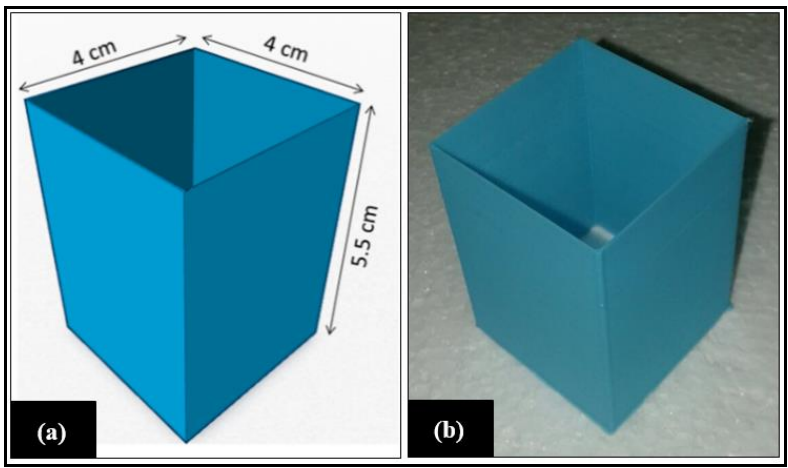

Fig. 3: FDM 3D printed part (a) geometry and (b) fabrication shape

\subsection{Surface Profile Measurements}

In this paper, the surface roughness amplitude parameters, which are independent of each other, were measured off-line quantitatively in $\mu \mathrm{m}$ from the filtered profiles. These amplitude parameters are average roughness, $R_{\mathrm{a}}$, root mean square, $R_{\mathrm{q}}$, skewness, $R_{\mathrm{sk}}$, and kurtosis, $R_{\mathrm{ku}}$. The surface roughness amplitude parameters were selected according to the recommendations in the literature review and with consideration of the data processing facilities available with differing levels of information [17-21].
The obtained data were reviewed and analyzed qualitatively with OriginLab $^{\circledR} 2017$ software. The measurement and resultant assessment of the desired FDM 3D printed part was successfully carried out according to international standards.

With an optimal combination of low contact force of $0.7 \mathrm{mN}$, high displacement sensitivity of $50 \mathrm{~nm}$ and the small tip radius of a 2 $\mu \mathrm{m}$ stylus being used in this study, the distribution of surface potential irregularities of the $0 \%$ infill density printed specimen was measured using a conventional contact-type Taly-Surf ${ }^{\circledR}$ profilometer from Taylor Hobson Precision, Inc. The examinations were performed under essentially wear-free and high-precision position measurement, which offered high resolution down to $0.8 \mathrm{~nm}$, a measuring range ( $x$-axis) of 12.5 $\mathrm{mm}$, and linear speed up to $0.5 \mathrm{~mm} / \mathrm{s}$. The traces were autolevelled, set up to a linear least-squares (LLS) straight line and then filtered with a standard low-pass of $0.8 \mathrm{~mm}$ cut-off wavelength. More details of the surface roughness measurement procedure have been reported elsewhere [22-31]. The high precision, repeatability and reproducibility of this technology make it appropriate for reverse engineering (RE) and roughness measurement.

\subsection{Procedure}

The surface measurement was conducted in three different zone levels (A, B, C) per each face (4-identical faces). Each zone was divided into three sub-zones on each face (A1, A2, A3 at zone A), (B1, B2, B3 at zone B) and (C1, C2, C3 at zone C). Zone (A) was located at $10 \mathrm{~mm}$ from the bottom of the printed part, zone (B) was in the middle of the printed part and zone (C) was located at $10 \mathrm{~mm}$ from the top of the printed part. All zones and sub-zones are in both inner and outer faces.

It is worth mentioning that $\mathrm{C} 1$ (corner no.1) represents the starting point of the printing process, whereas $\mathrm{C} 4$ (corner no.4) represents the ending point of the printing process. So, $\mathrm{C} 1$ to $\mathrm{C} 2$ represents face no.1, $\mathrm{C} 2$ to $\mathrm{C} 3$ represents face no.2, $\mathrm{C} 3$ to $\mathrm{C} 4$ represents face no.3, and finally, $\mathrm{C} 4$ to $\mathrm{C} 1$ represents face no. 4 for both inner and outer faces.

A total of 72 points are to be measured as shown in Figure 4 (36 points in the outer four identical faces and another 36 points in the inner four identical faces). Since the physical properties of a number of materials such as long-fiber thermoplastics can vary depending on the ambient temperature, tests were carried out in this study according to the standards for room temperature at $25 \pm 1{ }^{\circ} \mathrm{C}$. The relative humidity during the tests was $40 \pm 5 \% \mathrm{RH}$. Typically, all experiments were accomplished based on a 'ball-onflat' arrangement applying a linear sliding contact at constant velocity over a specific distance of $10 \mathrm{~mm}$, which is very close to the size of a human index fingertip. Tests were carried out by using single scan mode (forward-commanded motion). Each assessment condition was repeated at least three times with $90^{\circ}$ angle measurement at new locations on the desired FDM 3D 
printed part surface in order to ensure the reproducibility of the obtained results. The new site was at least within approximately $\pm 200 \mu \mathrm{m}$ from the previous one. This method is thus likely to avoid any modification of the counter-body surface, e.g., due to wear or friction, which might happen throughout the experiment and affect the measurements in the following tests.

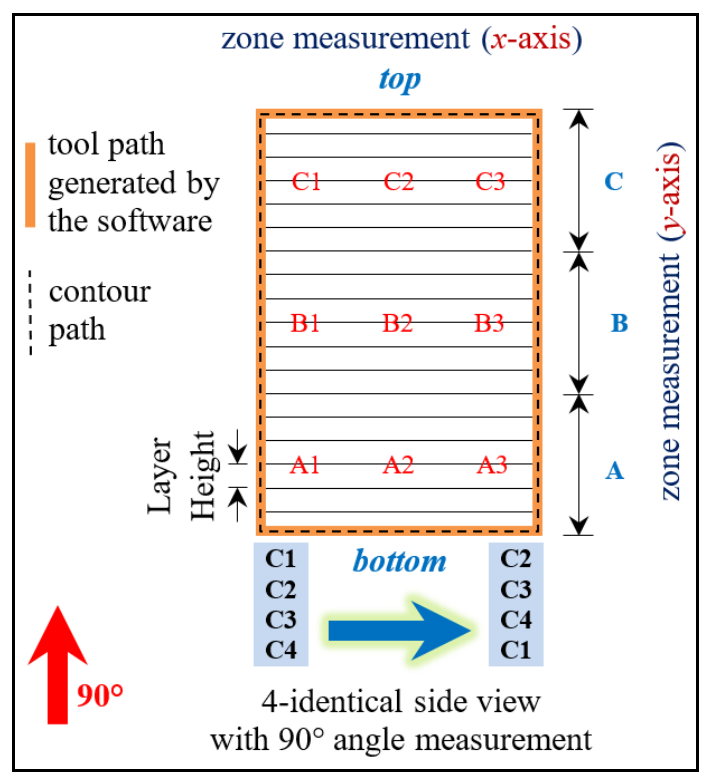

Fig. 4: FDM 3D printed part with a 4-idintical side view

\section{Experimental Results and Analysis}

Once the FDM 3D printed part was built using a double-sided adhesive on the glass platform to avoid the warping issue and cooled down to an ambient room temperature, the $0 \%$ infill density printed part was removed from the glass platform and the measurement performance was conducted at a distance of $55 \mathrm{~mm}$ at least three times on each zone and sub-zone levels, and the average values were considered. Deviation from each measurement is calculated and presented in the form of mean and standard deviation (mean $\pm \mathrm{SD}$ ). All FDM 3D printed part surface roughness was measured in an angular position of $90^{\circ}$ to build direction (from bottom to top). The experimental observations are discussed in the following section. In this trial, no warping deformation around each corner was observed.

\subsection{Surface Roughness Performance}

Figure 5 shows the surface roughness performance of the inner 4 identical faces at zone A, zone B and zone $\mathrm{C}$ while Figure 6 shows the surface roughness performance of the outer 4-identical faces at zone $\mathrm{A}$, zone $\mathrm{B}$ and zone $\mathrm{C}$.

At the inner 4-identical faces, as shown in Figure 5, face no.1 (C1 - $\mathrm{C} 2$ ) at sub-zone $\mathrm{C} 1$ represents the highest surface roughness by reaching $50.39 \mu \mathrm{m}$ followed by sub-zone A1 and sub-zone B1 by $38.13 \mu \mathrm{m}$ and $34.60 \mu \mathrm{m}$, respectively. This is, despite the low nozzle diameter of $0.5 \mathrm{~mm}$, suggestive of a slight effect of the circular nozzle diameter on the surface roughness distribution. It is worth mentioning that sub-zones A1 (bottom area), B1 (middle area) and $\mathrm{C} 1$ (top area) represent the starting point for each layer starting from the bottom to the top. In the FDM 3D process, the amount of PLA+ thermoplastic filament material that flows out at each point of departure (layer or path) from the circular nozzle is usually more in quantity due to unbalanced pressure at the FDM 3D system or some remaining thermoplastic filament material from the previous layer or path. In contrast, face no.4 (C4 - C1) at sub-zone $\mathrm{C} 1$ represents the lowest surface roughness by reaching $31.77 \mu \mathrm{m}$ followed by sub-zone $\mathrm{C} 2$ and sub-zone B3 by $31.95 \mu \mathrm{m}$ and $32.09 \mu \mathrm{m}$, respectively. Roughly speaking, face no.1 (C1 $\mathrm{C} 2$ ) represents the highest mean surface roughness of 36.62 \pm 5.41 $\mu \mathrm{m}$ while face no.4 (C4 - C1) decreases by almost $11.9 \%$ representing the lowest mean surface roughness of $32.26 \pm 0.32 \mu \mathrm{m}$ This roughness also depends on machine repeatability and preci- sion, and these are, therefore, the critical issues to be taken into account. At the same time, the effects of the contraction of deposited layers on cooling (the solidification process) should also be taken into account as mentioned earlier along with the fact that a seam is formed when transiting from one layer to the next layer. Such seams are extremely noticeable in thin printed objects.

At the outer 4-identical faces, as shown in Figure 6, face no.1 (C1 - C2) at sub-zone $\mathrm{C} 1$ represents the highest surface roughness by reaching $52.93 \mu \mathrm{m}$ followed by sub-zone $\mathrm{A} 1$ and sub-zone $\mathrm{C} 2$ by $34.66 \mu \mathrm{m}$ and $34.34 \mu \mathrm{m}$, respectively. Sub-zone C1, which belongs to face no. 1 in the outer face seems to be too coarse and wavy as well indicating that at the top area (zone C) there was some remaining PLA+ thermoplastic filament material from the previous layer or path. In contrast, face no.1 (C1 - C2) at sub-zone A3 represents the lowest surface roughness by reaching $31.16 \mu \mathrm{m}$ followed by sub-zone B3 and sub-zone C3 by $31.21 \mu \mathrm{m}$ and 31.36 $\mu \mathrm{m}$, respectively. Roughly speaking, face no.1 (C1 - C2) represents the highest mean surface roughness of $34.72 \pm 6.96 \mu \mathrm{m}$ while face no.2 (C2 - C3) decreases by almost $7.92 \%$ representing the lowest mean surface roughness of almost $31.97 \pm 0.34 \mu \mathrm{m}$.

As can be observed from Figures 5 and 6 , face no.1 (sub-zones A1, B1, C1) has the highest surface roughness which is the starting point for each layer for both inner and outer faces. Also, it has been shown that the inner surface roughness is higher than the outer surface roughness by almost $2.89 \%$. Moreover, the inner face no.2 (C2 - C3) and face no.3 (C3 - C4) fluctuate roughly between $32 \mu \mathrm{m}$ and $34 \mu \mathrm{m}$. However, the outer face no.2 (C2 C3) and face no. $3(\mathrm{C} 3$ - C4) fluctuate roughly between $31 \mu \mathrm{m}$ and $33 \mu \mathrm{m}$ leading to a $1 \mu \mathrm{m}$ difference between the inner and outer faces as shown in Figure 7. This is due to more heat being contained inside the FDM 3D printed part causing the inner face to have a higher surface roughness which is known as turbulent ambient temperature. This scenario proved that the outer face surface will always be better than the inner face surface. 


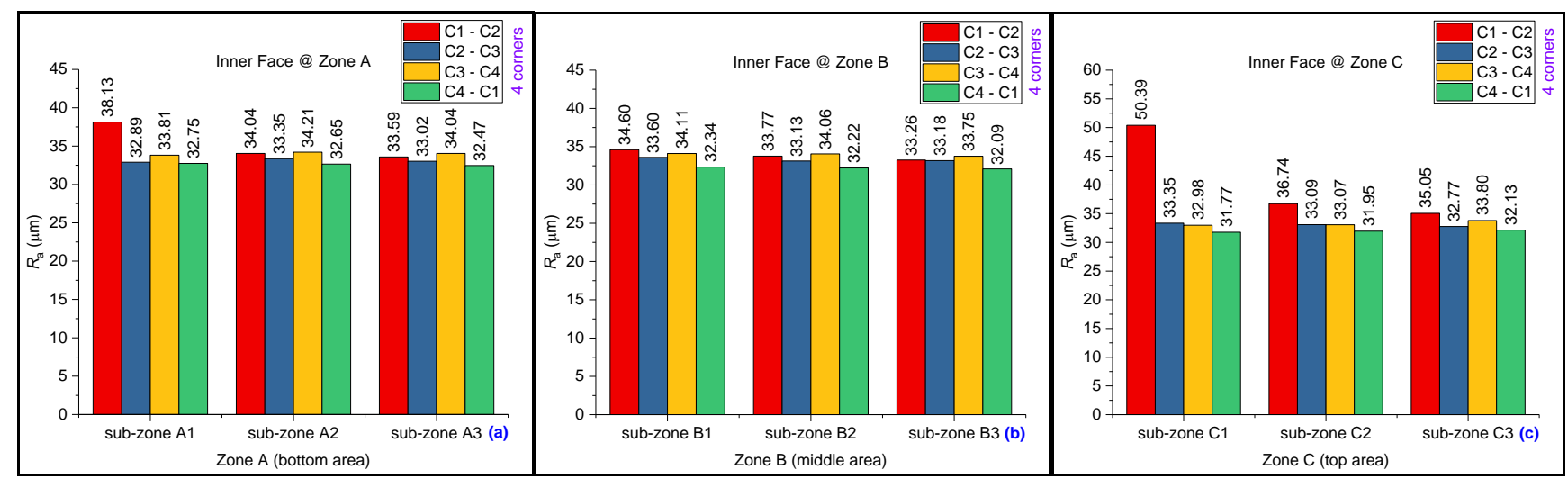

Fig. 5: surface roughness of inner 4-identical faces at (a) sub-zone A, (b) sub-zone $B$ and (c) sub-zone $C$

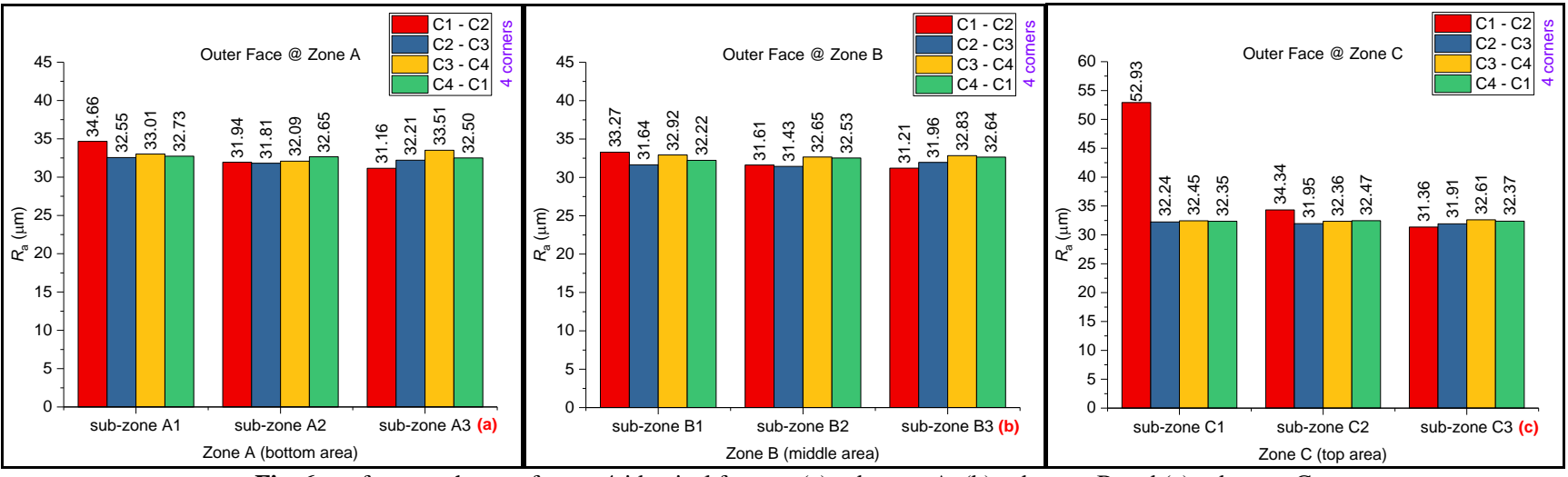

Fig. 6: surface roughness of outer 4-identical faces at (a) sub-zone A, (b) sub-zone B and (c) sub-zone C

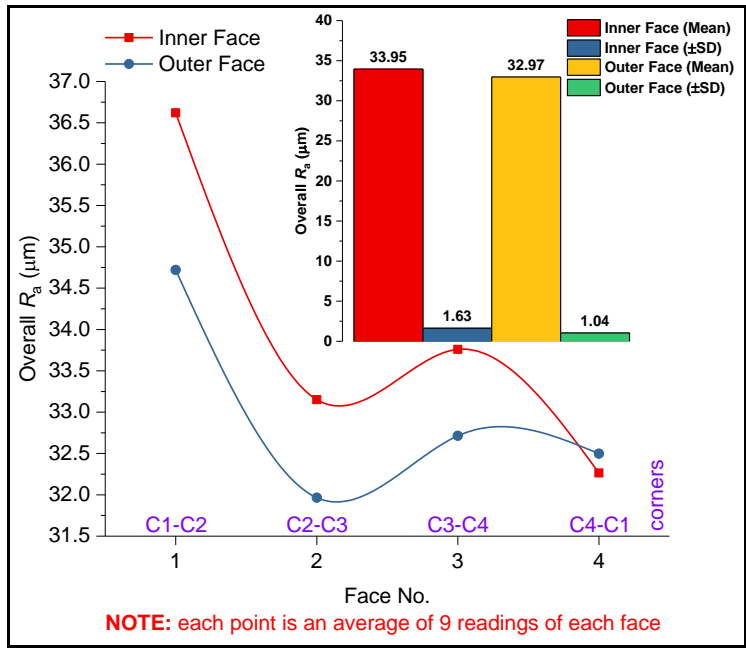

Fig. 7: overall mean surface roughness of both inner and outer 4-identical faces
Here, Table 2 shows the mean and standard deviation (mean $\pm \mathrm{SD}$ ) of the surface roughness, $R_{\mathrm{a}}$, for the inner faces in each zone A, B, and $\mathrm{C}$. At zone A, the surface roughness fluctuates roughly between 32 and $35 \mu \mathrm{m}$ with an average deviation of $\pm 0.77 \mu \mathrm{m}$. At zone $\mathrm{B}$, the surface roughness fluctuates roughly between 32 and $34 \mu \mathrm{m}$ with an average deviation of $\pm 0.32 \mu \mathrm{m}$. At zone C, it fluctuates roughly between 31 and $40 \mu \mathrm{m}$ with an average deviation of $\pm 2.3 \mu \mathrm{m}$. This indicated that zone $\mathrm{C}$ has the highest fluctuation of surface roughness with high standard deviation.

Table 3, meanwhile, shows the mean and standard deviation (mean $\pm \mathrm{SD}$ ) of the surface roughness, $R_{\mathrm{a}}$, for the outer faces in each zone A, B and C. At zone A, the surface roughness fluctuates roughly around $32 \mu \mathrm{m}$ with an average deviation of $\pm 0.76 \mu \mathrm{m}$. At zone $\mathrm{B}$, the surface roughness fluctuates roughly around $32 \mu \mathrm{m}$ which is the same as zone A with a less average deviation of \pm 0.43 $\mu \mathrm{m}$. At zone $\mathrm{C}$, meanwhile, it fluctuates roughly between 32 and $40 \mu \mathrm{m}$ with an average deviation of $\pm 3.0 \mu \mathrm{m}$. This indicated that zone $\mathrm{C}$ has the highest fluctuation of surface roughness with high standard deviation, which is consistent with inner faces.

Table 2: surface roughness of inner faces $(m e a n \pm \mathrm{SD})$

\begin{tabular}{|c|c|c|c|c|c|c|}
\hline \multirow{3}{*}{ Inner Faces } & \multicolumn{6}{|c|}{ Surface Roughness, $R_{\mathrm{a}}, \boldsymbol{\mu \mathrm { m }}$} \\
\hline & \multicolumn{2}{|c|}{ Zone A (bottom area) } & \multicolumn{2}{|c|}{ Zone B (middle area) } & \multicolumn{2}{|c|}{ Zone C (top area) } \\
\hline & Mean & $\pm \mathrm{SD}$ & Mean & $\pm \mathrm{SD}$ & Mean & $\pm \mathrm{SD}$ \\
\hline C1 - C2 & 35.26 & 2.50 & 33.88 & 0.68 & 40.73 & 8.41 \\
\hline $\mathrm{C} 2-\mathrm{C} 3$ & 33.09 & 0.24 & 33.30 & 0.26 & 33.07 & 0.29 \\
\hline C3 - C4 & 34.02 & 0.20 & 33.97 & 0.19 & 33.28 & 0.45 \\
\hline C4 - C1 & 32.62 & 0.14 & 32.22 & 0.13 & 31.95 & 0.18 \\
\hline
\end{tabular}

Table 3: surface roughness of outer faces (mean $\pm \mathrm{SD})$

\begin{tabular}{|c|c|c|c|c|c|c|}
\hline \multirow{3}{*}{ Outer Faces } & \multicolumn{6}{|c|}{ Surface Roughness, $\boldsymbol{R}_{\mathrm{a}}, \boldsymbol{\mu \mathrm { m }}$} \\
\hline & \multicolumn{2}{|c|}{ Zone A (bottom area) } & \multicolumn{2}{|c|}{ Zone B (middle area) } & \multicolumn{2}{|c|}{ Zone $\mathbf{C}$ (top area) } \\
\hline & Mean & $\pm \mathrm{SD}$ & Mean & $\pm \mathrm{SD}$ & Mean & $\pm \mathrm{SD}$ \\
\hline C1 - C2 & 32.59 & 1.84 & 32.03 & 1.10 & 39.54 & 11.69 \\
\hline $\mathrm{C2}-\mathrm{C} 3$ & 32.19 & 0.37 & 31.67 & 0.27 & 32.03 & 0.18 \\
\hline $\mathrm{C3}$ - C4 & 32.87 & 0.72 & 32.80 & 0.14 & 32.47 & 0.12 \\
\hline C4 - C1 & 32.63 & 0.12 & 32.47 & 0.22 & 32.40 & 0.06 \\
\hline
\end{tabular}




\section{2. $\boldsymbol{R}_{\mathbf{q}} / \boldsymbol{R}_{\mathrm{a}}$ Ratio Performance}

Analysis of the surface profiles generated under manufacturing process parameters conditions is conducted qualitatively in terms of the static characteristics in three different zone levels (A, B, C) and sub-zone levels (A1, A2, A3), (B1, B2, B3) and (C1, C2, C3), including the surface roughness, $R_{\mathrm{a}}$, and the root mean square, $R_{\mathrm{q}}$, to generate the ratio performance of the surface profile $R_{\mathrm{q}} / R_{\mathrm{a}}$ with the process parameters of an FDM 3D machine. During the assessment, the detailed texture of the newly created surface must be considered. Based on the values of the surface roughness discussed in this paper, the values of amplitude parameters in each zone and sub-zone were slightly different between the inner and outer faces. For this reason, the values of the amplitude in three zones and sub-zones were measured on each four-identical inner and outer faces.

Figure 8 shows the $R_{\mathrm{q}} / R_{\mathrm{a}}$ ratio performance of inner faces and outer faces at zone A, B, and C. It is worth mentioning that each zone is an average value relating to sub-zone levels while Figure 9 shows the overall $R_{\mathrm{q}} / R_{\mathrm{a}}$ ratio performance of inner faces and outer faces at each face.

At the inner 4-identical faces as illustrated in figure 8(a), the maximum ratio of root means square, $R_{\mathrm{q}}$, to average surface roughness, $R_{\mathrm{a}}$, was found to be $1.21 \pm 0.03$ at face no.1 (zone C) while the minimum ratio of root means square (RMS), $R_{\mathrm{q}}$, to average surface roughness, $R_{\mathrm{a}}$, was found to be $1.17 \pm 0.001$ at face no.2 (zone A). It also showed non-uniform and irregularity behaviour of $R_{\mathrm{q}} / R_{\mathrm{a}}$ ratio performance distribution over each face during the building process.

At the outer 4-identical faces as illustrated in figure $8(\mathrm{~b})$, the maximum ratio of root means square, $R_{\mathrm{q}}$, to average surface roughness, $R_{\mathrm{a}}$, was found to be $1.21 \pm 0.02$ at face no.1 (zone C) while the minimum ratio of root means square (RMS), $R_{\mathrm{q}}$, to average surface roughness, $R_{\mathrm{a}}$, was found to be $1.16 \pm 0.001$ at face no.2 (zone B). Notice that faces no. 2, 3, and 4 show the roughly normal behaviour pattern of $R_{\mathrm{q}} / R_{\mathrm{a}}$ ratio performance of almost $1.17 \pm 0.001$ whereas face no. 1 shows the non-uniform distribution of almost 1.2 \pm 0.02 . As can be observed in Figure 8, on the basis of this set of values, the ratio $R_{\mathrm{q}} / R_{\mathrm{a}}$ is roughly the same for both inner and outer faces however the inner faces are more irregular while the outer faces are consistent with each other.

Figure 9(a) shows that the overall $R_{\mathrm{q}} / R_{\mathrm{a}}$ ratio of the inner face was found to be $1.1993 \pm 0.0265$ at face no.1, which represents an average value of nine reading over a distance of $55 \mathrm{~mm}$, and Figure 9(b) reveals that the overall $R_{\mathrm{q}} / R_{\mathrm{a}}$ ratio of the outer face was found to be $1.2065 \pm 0.0212$ at face no.1, indicating that the outer face has a higher ratio of $0.6 \%$. In contrast, the other faces for both inner and outer are relatively the same in comparison to each other as regards the overall value of $R_{\mathrm{q}} / R_{\mathrm{a}}$ at around $1.17 \pm 0.0035$.

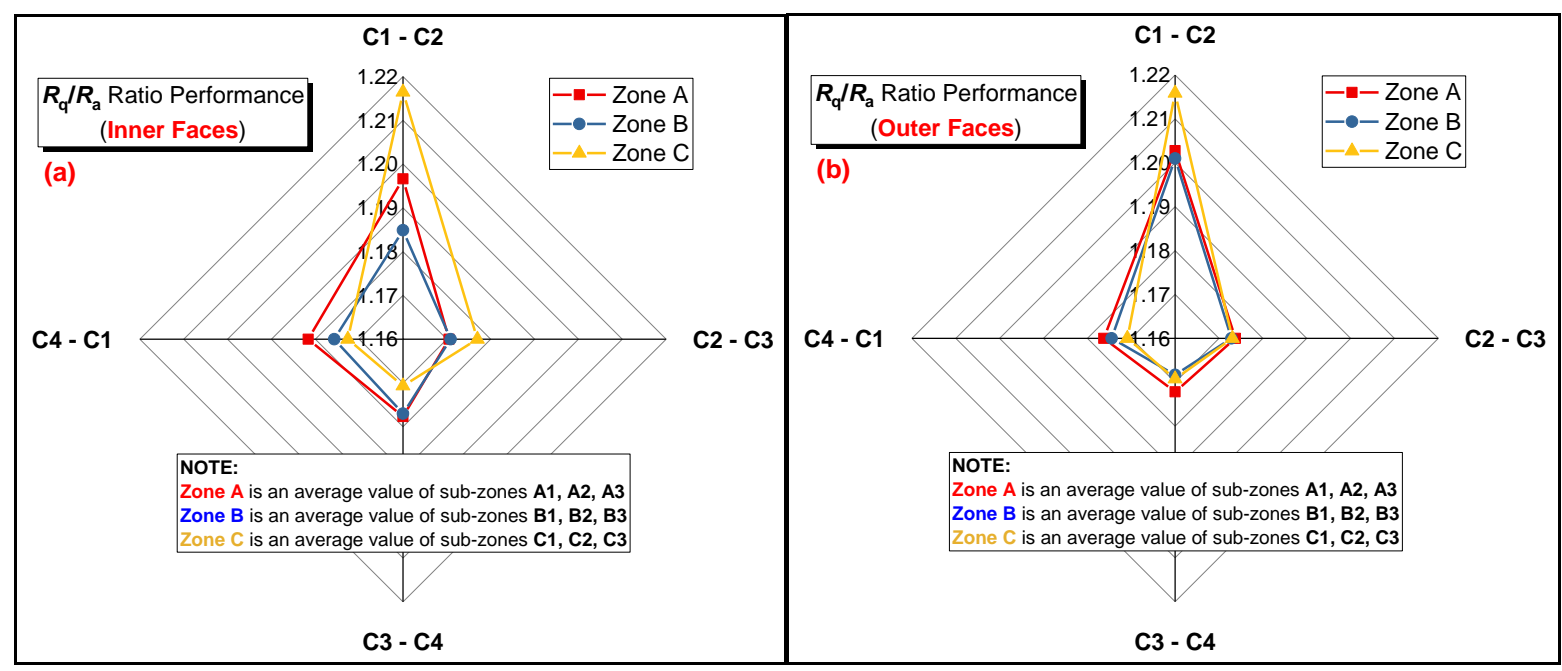

Fig. 8: ratio performance of (a) inner faces and (b) outer faces at zone A, B, and C
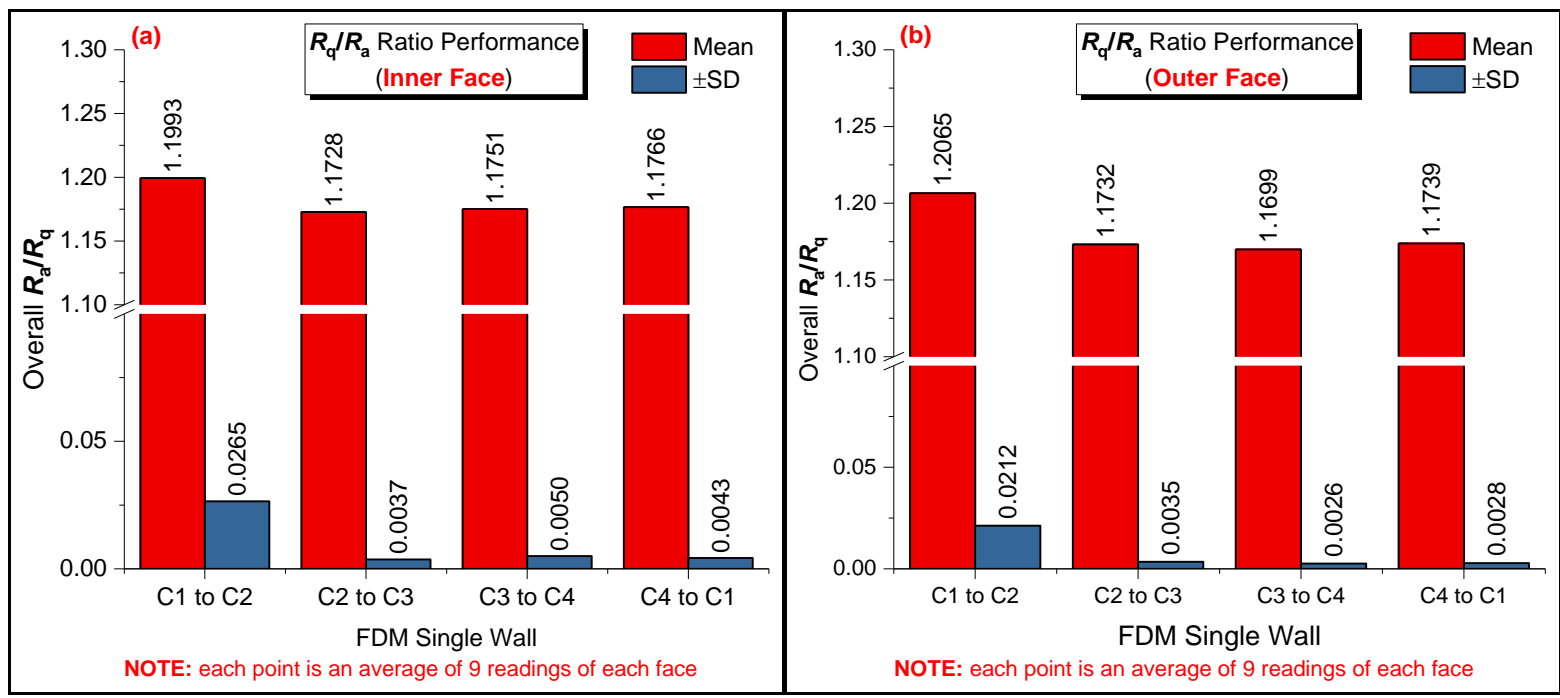

Fig. 9: overall ratio performance of (a) inner faces and (b) outer faces at each face 


\subsection{Skewness vs. Kurtosis Performance}

The third-order and fourth-order central moments are skewness, $R_{\mathrm{sk}}$, ( ${ }^{\text {rd }}$ moment) and kurtosis, $R_{\mathrm{ku}}$, (4 $4^{\text {th }}$ moment), accordingly; both provide more information on the real profile of an FDM 3D printed part, which are both going to be discussed here.

Skewness is defined by ISO 4287 (1997) [32] as it evaluates the degree of asymmetry distribution and is categorised as positive skewness (surfaces are 'empty' of material) or negative skewness (surfaces are 'full' of material). It is a significant parameter for tribological applications, such as friction, wear and lubrication. A Gaussian distribution presents $R_{\mathrm{sk}}=0$.

Kurtosis is defined by ISO 4287 (1997) [32] as it defines the distribution sharpness with $R_{\mathrm{ku}}=3$ for the normal distribution. The surface is dominated by sharp peaks (spiky) when $R_{\mathrm{ku}}>3$, whereas the surface is dominated by bumpy peaks when $R_{\mathrm{ku}}<3$. In this respect, it is a significant parameter as regards providing information on the real area of thermoplastic contact material and wear resistance. Also, it is more likely to distinguish the periodicity of the profile $\left(R_{\mathrm{ku}}<3\right)$.

Tables 4 and 5 show the mean values of skewness and kurtosis for both the inner and the outer faces at zone A (A1, A2, A3), zone B $(\mathrm{B} 1, \mathrm{~B} 2, \mathrm{~B} 3)$ and zone $\mathrm{C}(\mathrm{C} 1, \mathrm{C} 2, \mathrm{C} 3)$ and these are presented in the form of mean and standard deviation (mean $\pm \mathrm{SD})$. All three different zone levels exhibit the consistency of a negatively skewed profile distribution with an almost full deposit of PLA+ thermoplastic filament material. However, the values of $R_{\mathrm{sk}}\left(3^{\text {rd }}\right.$ moment) for the inner face is higher than that of the outer face, while the $R_{\mathrm{ku}}\left(4^{\text {th }}\right.$ moment) relatively remain constant for both the inner and the outer faces.

Table 4: skewness and kurtosis of inner faces (mean \pm SD)

\begin{tabular}{|c|c|c|c|c|c|c|}
\hline \multirow{3}{*}{ Inner Faces } & \multicolumn{6}{|c|}{ Skewness, $\boldsymbol{R}_{\text {sk }}$} \\
\hline & \multicolumn{2}{|c|}{$\begin{array}{c}\text { Zone A } \\
\text { (bottom area) }\end{array}$} & \multicolumn{2}{|c|}{$\begin{array}{c}\text { Zone B } \\
\text { (middle area) }\end{array}$} & \multicolumn{2}{|c|}{$\begin{array}{c}\text { Zone C } \\
\text { (top area) }\end{array}$} \\
\hline & Mean & $\pm \mathrm{SD}$ & Mean & $\pm \mathrm{SD}$ & Mean & $\pm \mathrm{SD}$ \\
\hline $\mathrm{C} 2-\mathrm{C} 3$ & -0.73 & 0.01 & -0.74 & 0.01 & -0.72 & 0.02 \\
\hline C3 - C4 & -0.68 & 0.05 & -0.67 & 0.02 & -0.72 & 0.01 \\
\hline C4 - C1 & -0.75 & 0.02 & -0.78 & 0.02 & -0.78 & 0.01 \\
\hline \multirow{3}{*}{ Inner Faces } & \multicolumn{6}{|c|}{ Kurtosis, $\boldsymbol{R}_{\mathrm{ku}}$} \\
\hline & \multicolumn{2}{|c|}{$\begin{array}{c}\text { Zone A } \\
\text { (bottom area) }\end{array}$} & \multicolumn{2}{|c|}{$\begin{array}{c}\text { Zone B } \\
\text { (middle area) }\end{array}$} & \multicolumn{2}{|c|}{$\begin{array}{c}\text { Zone C } \\
\text { (top area) }\end{array}$} \\
\hline & Mean & $\pm \mathrm{SD}$ & Mean & $\pm \mathrm{SD}$ & Mean & $\pm \mathrm{SD}$ \\
\hline $\mathrm{C} 1$ - C2 & 2.27 & 0.04 & 2.29 & 0.12 & 2.50 & 0.36 \\
\hline $\mathrm{C} 2$ - C3 & 2.22 & 0.01 & 2.22 & 0.01 & 2.25 & 0.01 \\
\hline C3 - C4 & 2.23 & 0.03 & 2.21 & 0.01 & 2.20 & 0.01 \\
\hline C4 - C1 & 2.33 & 0.01 & 2.29 & 0.01 & 2.27 & 0.02 \\
\hline
\end{tabular}

Table 5: skewness and kurtosis of outer faces (mean \pm SD)

\begin{tabular}{|c|c|c|c|c|c|c|}
\hline \multirow{3}{*}{ Outer Faces } & \multicolumn{6}{|c|}{ Skewness, $\boldsymbol{R}_{\mathrm{sk}}$} \\
\hline & \multicolumn{2}{|c|}{$\begin{array}{c}\text { Zone A } \\
\text { (bottom area) }\end{array}$} & \multicolumn{2}{|c|}{$\begin{array}{c}\text { Zone B } \\
\text { (middle area) }\end{array}$} & \multicolumn{2}{|c|}{$\begin{array}{c}\text { Zone C } \\
\text { (top area) }\end{array}$} \\
\hline & Mean & $\pm \mathrm{SD}$ & Mean & $\pm \mathrm{SD}$ & Mean & $\pm \mathrm{SD}$ \\
\hline $\mathrm{C} 1$ - C2 & -0.50 & 0.16 & -0.54 & 0.21 & -0.24 & 0.35 \\
\hline $\mathrm{C} 2$ - C3 & -0.62 & 0.03 & -0.68 & 0.02 & -0.65 & 0.01 \\
\hline $\mathrm{C} 3$ - C4 & -0.69 & 0.04 & -0.69 & 0.02 & -0.71 & 0.02 \\
\hline C4 - C1 & -0.71 & 0.01 & -0.71 & 0.02 & -0.74 & 0.01 \\
\hline \multirow{3}{*}{ Outer Faces } & \multicolumn{6}{|c|}{ Kurtosis, $\boldsymbol{R}_{\mathrm{ku}}$} \\
\hline & \multicolumn{2}{|c|}{$\begin{array}{c}\text { Zone A } \\
\text { (bottom area) }\end{array}$} & \multicolumn{2}{|c|}{$\begin{array}{c}\text { Zone B } \\
\text { (middle area) }\end{array}$} & \multicolumn{2}{|c|}{$\begin{array}{c}\text { Zone C } \\
\text { (top area) }\end{array}$} \\
\hline & Mean & $\pm \mathrm{SD}$ & Mean & $\pm \mathrm{SD}$ & Mean & $\pm \mathrm{SD}$ \\
\hline $\mathrm{C} 1$ - C2 & 2.29 & 0.04 & 2.42 & 0.21 & 2.44 & 0.23 \\
\hline $\mathrm{C} 2$ - C3 & 2.15 & 0.05 & 2.20 & 0.00 & 2.16 & 0.03 \\
\hline C3 - C4 & 2.22 & 0.00 & 2.19 & 0.00 & 2.19 & 0.01 \\
\hline C4 - C1 & 2.24 & 0.01 & 2.23 & 0.01 & 2.21 & 0.01 \\
\hline
\end{tabular}

Figure 10 shows that the plot of $R_{\mathrm{sk}}\left(3^{\text {rd }}\right.$ moment) against $R_{\mathrm{ku}}\left(4^{\text {th }}\right.$ moment) of the FDM 3D printed part generated profile is centred around the random Gaussian profile, which was only negatively skewed distribution in the inner faces and mostly negative and positive skewed distribution in the outer faces and both inner and outer faces having platykurtic distribution with a low degree of peakedness.

Figure 10 (a) shows the plot of $R_{\mathrm{sk}}\left(3^{\text {rd }}\right.$ moment) against $R_{\mathrm{ku}}\left(4^{\text {th }}\right.$ moment) for the inner faces of the FDM 3D printed part. It can be seen that the general trend is a negatively skewed distribution with a low degree of peakedness. Also, the general trend of skewness and kurtosis is in the region of $-0.8 \leq R_{\mathrm{sk}} \leq-0.6$ with some irregularities for face no.1 (inner face) being higher in the region of $-0.5 \leq R_{\mathrm{sk}} \leq-0.3$ (100\% negatively skewed distribution) and $2.20 \leq R_{\mathrm{ku}} \leq 2.45(100 \%$ platykurtic distribution with a low degree of peakedness) with a range of 0.5 and 0.25 for $R_{\mathrm{sk}}$ and $R_{\mathrm{ku}}$, respectively.

Figure 10(b) shows the plot of $R_{\mathrm{sk}}\left(3^{\text {rd }}\right.$ moment) against $R_{\mathrm{ku}}\left(4^{\text {th }}\right.$ moment) for the outer faces of the FDM 3D printed part. The general trend is mostly negatively and some positively skewed distribution with a low degree of peakedness. Also, the general trend of skewness and kurtosis is in the region of $-0.75 \leq R_{\mathrm{sk}} \leq-0.55$ with some irregularities as regards face no.1 (outer face, $\mathrm{C} 1-\mathrm{C} 2$ ) being higher in the region of $-0.35 \leq R_{\mathrm{sk}} \leq 0.1(88.2 \%$ negatively skewed distribution and $11.8 \%$ positively skewed distribution) and $2.10 \leq$ $R_{\mathrm{ku}} \leq 2.75$ (100\% platykurtic distribution with low degree of peakedness) with a range of 0.85 and 0.65 for $R_{\mathrm{sk}}$ and $R_{\mathrm{ku}}$, respectively. It is worth mentioning that the $R_{\mathrm{sk}} \approx 0.1$ indicating that this value has deeper-larger amplitude profile valleys than the rest of the DM 3D printed parts.

It is shown that face no. $1(\mathrm{C} 1-\mathrm{C} 2)$ for both inner and outer faces have a higher $R_{\mathrm{sk}}$ and $R_{\mathrm{ku}}$ which is in line with the data obtained from $R_{\mathrm{a}}$ and $R_{\mathrm{q}}$.

Figure 11 shows the overall value of $R_{\mathrm{sk}}\left(3^{\text {rd }}\right.$ moment) and $R_{\mathrm{ku}}\left(4^{\text {th }}\right.$ moment) for both the inner and the outer faces of the FDM 3D printed part. The mean value of $R_{\mathrm{sk}}\left(3^{\text {rd }}\right.$ moment) and its standard deviation as shown in Figure 11(a) for both inner and outer faces were found to be $-0.68 \pm 0.08$ and $-0.62 \pm 0.12$, respectively, indicating that the inner face was slightly fuller of PLA+ thermoplastic filament material than the outer face. On the other hand, the mean value of $R_{\mathrm{ku}}\left(4^{\text {th }}\right.$ moment) and its standard deviation as shown in Figure 11(b) for both inner and outer faces was found to be 
$2.27 \pm 0.10$ and $2.25 \pm 0.08$, respectively, indicating that both the inner and outer faces have platykurtic distribution profile, and that the peaks are bumpy with low degree of peakedness.

Clearly, it can be concluded that most of the surfaces, regardless of their process parameters of the personal FDM 3D machine, are characterized by small values of skewness and kurtosis with negatively skewed distribution (surfaces are 'full' of thermoplastic filament material).

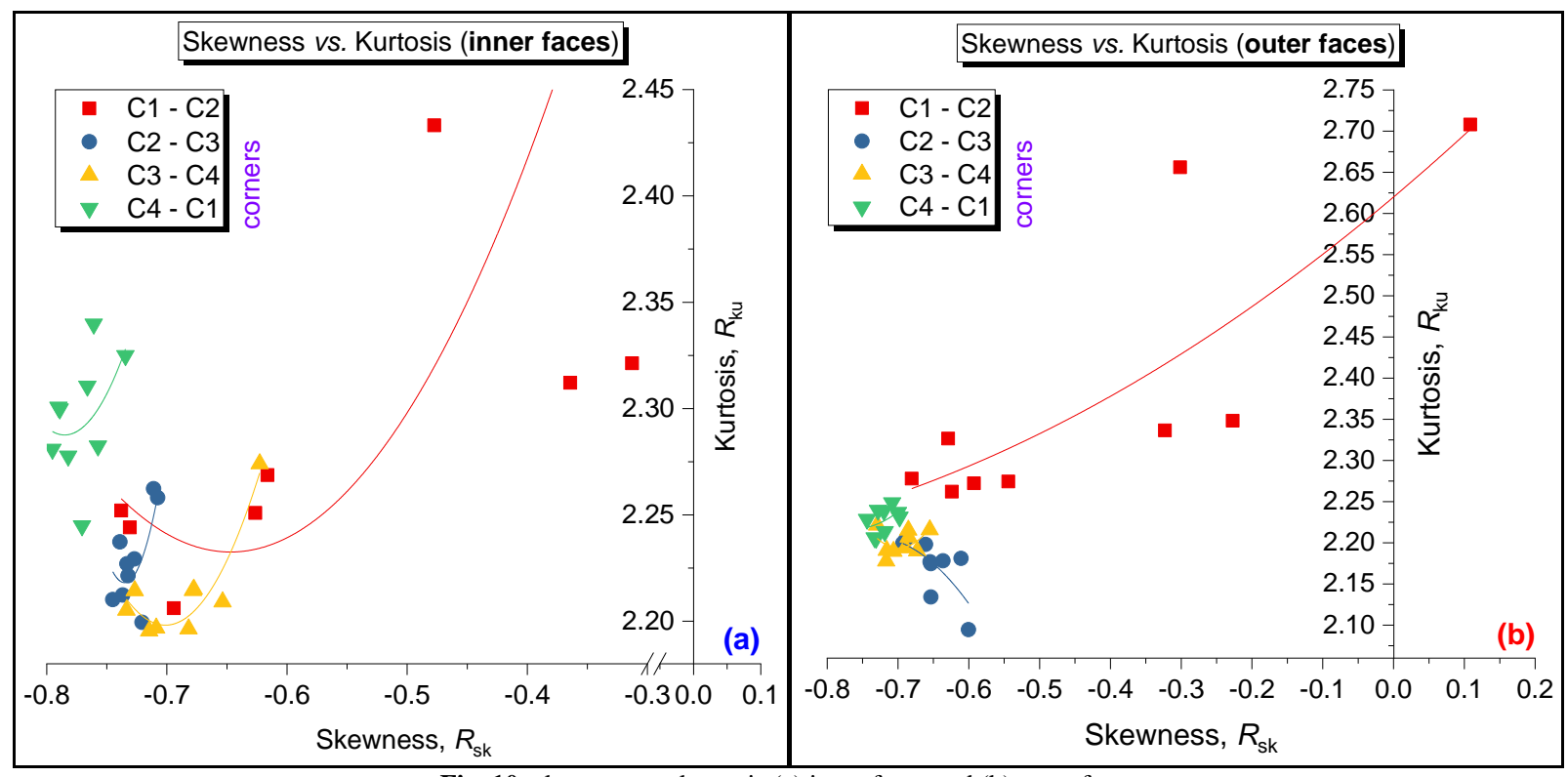

Fig. 10: skewness $v s$. kurtosis (a) inner faces and (b) outer faces

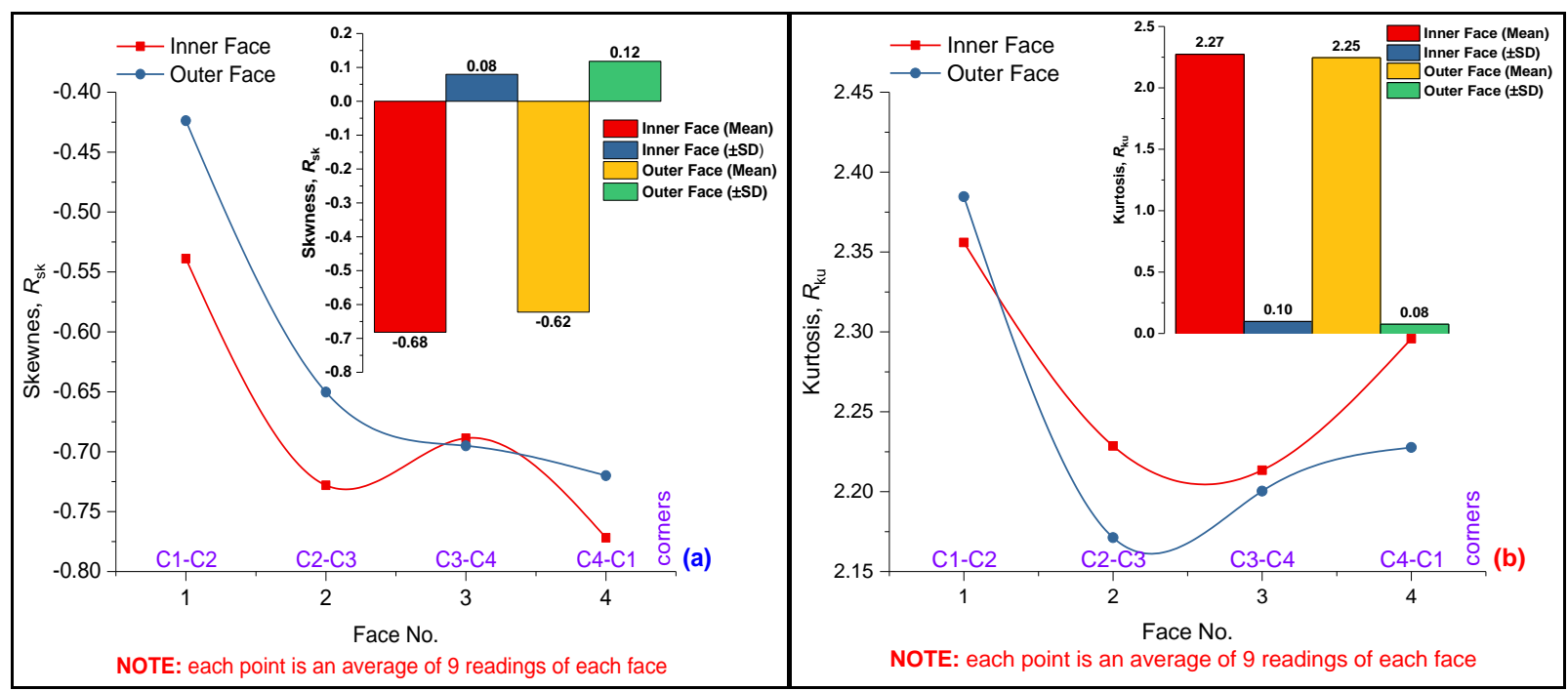

Fig. 11: overall mean of both inner and outer 4-identical faces for (a) skewness (b) kurtosis

\section{Conclusions}

The use of personal FDM 3D printing technology for RP has promised to produce components with very complex shapes according to computer design software for low-cost printers. The purpose of this research is to study quantitively the surface finish of $0 \%$ infill density printed part from both inner and outer faces, as this aspect is essential for the future of this new thriving market segment. Based on the experimental results obtained in this paper, the following conclusions were arrived at:

- The starting point of each layer exhibits a higher surface roughness, $R_{\mathrm{a}}$, distribution value for both inner and outer faces especially in face no.1 (C1 - C2).

- The inner faces have a higher overall surface roughness than the outer faces by almost $1 \mu \mathrm{m}(\sim 3 \%)$ for all 4 identical faces.

- The outer faces $R_{\mathrm{q}} / R_{\mathrm{a}}$ ratio performance values tend to follow the same pattern while the inner faces values are usually scattered. Nonetheless, the overall $R_{\mathrm{q}} / R_{\mathrm{a}}$ ratio performance value is the same with only a $0.006 \%$ difference.
- The general trend of FDM 3D printed part with PLA+ thermoplastic filament material as a model material for skewness, $R_{\mathrm{sk}}$, ( $3^{\text {rd }}$ moment) has a negatively skewed frequency distribution and also the kurtosis, $R_{\mathrm{ku}}$, $\left(4^{\text {th }}\right.$ moment) has a platykurtic frequency distribution with a low degree of peakedness.

As a final conclusion, due to the turbulent ambient temperature in the inner structure of the printed part causing inconsistent heat circulation, so the inner faces have a slow and inconsistent solidification process leading to a higher surface roughness than the outer faces which are affected by laminar ambient temperature where there is consistent cooling rate leading to a smoother surface distribution profile.

Further work is in progress towards analysis of the surface profile in the personal FDM 3D printer, which will use layer-by-layer deposition, of $100 \%$ infill density in $0^{\circ}, 45^{\circ}$ and $90^{\circ}$ angle measurement for both inner and outer 4-identical faces. 


\section{Conflicts of Interest}

The authors have no conflicts of interest.

\section{Funding}

The authors received no financial support for the research and/or for the publication of this article.

\section{References}

[1] Williams, R. E., et al., Investigation of the effect of various build methods on the performance of rapid prototyping (stereolithography). Journal of Materials Processing Technology, 1996. 61(1): p. 173-178.

[2] Byun, H.-S. and K.H. Lee, Determination of the optimal build direction for different rapid prototyping processes using multicriterion decision making. Robotics and Computer-Integrated Manufacturing, 2006. 22(1): p. 69-80.

[3] Liu, X. and V. Shapiro, Homogenization of material properties in additively manufactured structures. Computer-Aided Design, 2016. 78: p. 71-82.

[4] Eisenberg, M., 3D printing for children: What to build next? International Journal of Child-Computer Interaction, 2013. 1(1): p. 7-13.

[5] Stansbury, J.W. and M.J. Idacavage, 3D printing with polymers: Challenges among expanding options and opportunities. Dental Materials, 2016. 32(1): p. 54-64.

[6] Abdelaal, O.A.M. and S.M.H. Darwish, Review of Rapid Prototyping Techniques for Tissue Engineering Scaffolds Fabrication, in Characterization and Development of Biosystems and Biomaterials, A. Öchsner, L.F.M. da Silva, and H. Altenbach, Editors. 2013, Springer Berlin Heidelberg: Berlin, Heidelberg. p. 33-54.

[7] Ryan, I. and B.W. Christopher, Design and manufacture of a Formula SAE intake system using fused deposition modeling and fiber-reinforced composite materials. Rapid Prototyping Journal, 2010. 16(3): p. 174-179.

[8] Vashishtha, V.K., R. Makade, and N. Mehla, Advancement of rapid prototyping in aerospace industry - a review. International Journal of Engineering Science and Technology, 2011. 3(3): p. 2486-2493.

[9] Galantucci, L.M., F. Lavecchia, and G. Percoco, Experimental study aiming to enhance the surface finish of fused deposition modeled parts. CIRP Annals - Manufacturing Technology, 2009. 58(1): p. 189-192.

[10] Mohamed, O.A., S.H. Masood, and J.L. Bhowmik, Mathematical modeling and FDM process parameters optimization using response surface methodology based on Q-optimal design. Applied Mathematical Modelling, 2016. 40(23): p. 10052-10073.

[11] Mostafa, M.A.G., M.S. Alsoufi, and B.A. Tayeb, CAD/CAM Integration Based on Machining Features for Prismatic Parts. International Journal of Emerging Trends \& Technology in Computer Science, 2015. 4(3): p. 106-110.

[12] Gardan, J., A. Makke, and N. Recho, A Method to Improve the Fracture Toughness Using 3D Printing by Extrusion Deposition Procedia Structural Integrity, 2016. 2: p. 144-151.

[13] Ahn, S.-H., et al., Anisotropic material properties of fused deposition modeling ABS. Rapid Prototyping Journal, 2002. 8(4): p. 248257.

[14] Alsoufi, M.S. and A.E. Elsyeed, Warping Deformation of Desktop 3D Printed Parts Manufactured by Open Source Fused Deposition Modeling (FDM) System. International Journal of Mechanical and Mechatronics Engineering, 2017. 17(4): p. 7-16.

[15] Alsoufi, M.S. and A.E. Elsayed, How Surface Roughness Performance of Printed Parts Manufactured by Desktop FDM 3D Printer with PLA+ is Influenced by Measuring Direction. American Journal of Mechanical Engineering, 2017. 5(5): p. 211-222.

[16] Alsoufi, M.S. and A.E. Elsayed, Surface Roughness Quality and Dimensional Accuracy - A Comprehensive Analysis of 100\% Infill Printed Parts Fabricated by a Personal/Desktop Cost-Effective FDM 3D Printer Materials Sciences and Applications, 2018. 9(1): p. 11-40.

[17] Dong, W.P., P.J. Sullivan, and K.J. Stout, Comprehensive study of parameters for characterizing three-dimensional surface topography I: Some inherent properties of parameter variation. Wear, 1992. 159(2): p. 161-171.

[18] Dong, W.P., P.J. Sullivan, and K.J. Stout, Comprehensive study of parameters for characterizing three-dimensional surface topogra- phy II: Statistical properties of parameter variation. Wear, 1993. 167(1): p. 9-21.

[19] Dong, W.P., P.J. Sullivan, and K.J. Stout, Comprehensive study of parameters for characterizing three-dimensional surface topography III: parameters for characterising amplitude and some functional properties. Wear, 1994. 178(1): p. 29-43.

[20] Dong, W.P., P.J. Sullivan, and K.J. Stout, Comprehensive study of parameters for characterising three-dimensional surface topography: IV: Parameters for characterising spatial and hybrid properties. Wear, 1994. 178(1): p. 45-60.

[21] Thomas, T.R., Characterization of surface roughness. Precision Engineering, 1981. 3(2): p. 97-104.

[22] Alsoufi, M.S. and T.M. Bawazeer, Quantifying assessment of touch-feel perception: an investigation using stylus base equipment and self-touch (human fingertip). Umm Al-Qura University: Journal of Engineering and Architecture, 2015. 1(1): p. 1-16.

[23] Alsoufi, M.S. and T.M. Bawazeer, The Effect of Aggressive Biological Materials on a Painted Automotive Body Surface Roughness. American Journal of Nano Research and Applications, 2015. 3(2): p. $17-26$.

[24] Suker, D.K., et al., Studying the Effect of Cutting Conditions in Turning Process on Surface Roughness for Different Materials. World Journal of Research and Review (WJRR), 2016. 2(4): p. 1621.

[25] Alsoufi, M.S., et al., Experimental Study of Surface Roughness and Micro-Hardness Obtained by Cutting Carbon Steel with Abrasive WaterJet and Laser Beam Technologies. American Journal of Mechanical Engineering, 2016. 4(5): p. 173-181.

[26] Bawazeer, T.M., et al., Effect of Aqueous Extracts of Salvadora Persica "Miswak" on the Acid Eroded Enamel Surface at NanoMechanical Scale. Materials Sciences and Applications, 2016. 7(11): p. 754-771.

[27] Alsoufi, M.S., et al., Surface Roughness and Knoop Indentation MicroHardness Behavior of Aluminium Oxide (Al2O3) and Polystyrene $\left(\mathrm{C}_{8} \mathrm{H}_{8}\right)_{n}$ Materials International Journal of Mechanical \& Mechatronics Engineering, 2016. 16(6): p. 43-49.

[28] Alsoufi, M.S., State-of-the-Art in Abrasive Water Jet Cutting Technology and the Promise for Micro- and Nano-Machining. International Journal of Mechanical Engineering and Applications, 2017. 5(1): p. 1-14.

[29] Alsoufi, M.S., et al., Influence of Abrasive Waterjet Machining Parameters on the Surface Texture Quality of Carrara Marble. Journal of Surface Engineered Materials and Advanced Technology, 2017. 7(2): p. 25-37.

[30] Alsoufi, M.S., et al., Abrasive WaterJet Machining of Thick Carrara Marble: Cutting Performance vs. Profile, Lagging and WaterJet Angle Assessments. Materials Sciences and Applications, 2017. 8(5): p. 361-375

[31] Alsoufi, M.S., et al., The Effect of Detergents on the Appearance of Automotive Clearcoat Systems Studied in an Outdoor Weathering Test Materials Sciences and Applications, 2017. 8(7): p. 521-536.

[32] ISO4287, Geometrical Product Specifications (GPS) -- Surface texture: Profile method -- Terms, definitions and surface texture parameters. 1997, ISO. 